\title{
Frontières
}

\section{Courte vie de Malcolm Walker (extraits)}

\section{Claire Varin}

Volume 18, numéro 1, automne 2005

Hélas, célébrer la mort!

URI : https://id.erudit.org/iderudit/1074321ar

DOI : https://doi.org/10.7202/1074321ar

Aller au sommaire du numéro

Éditeur(s)

Université du Québec à Montréal

ISSN

1180-3479 (imprimé)

1916-0976 (numérique)

Découvrir la revue

Citer ce document

Varin, C. (2005). Courte vie de Malcolm Walker (extraits). Frontières, 18(1),

70-71. https://doi.org/10.7202/1074321ar d'utilisation que vous pouvez consulter en ligne.

https://apropos.erudit.org/fr/usagers/politique-dutilisation/ 


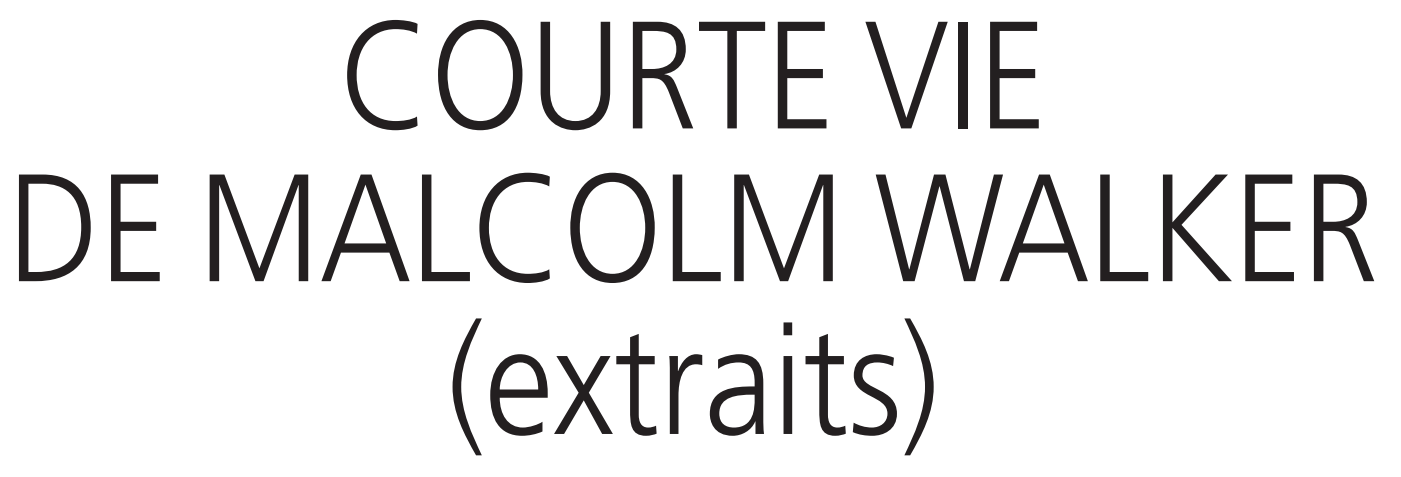

Claire Varin, Ph.D., écrivaine*

Le Mexique se trouve dans ma mire alors que je reviens vers toi en écriture, dans ce mouvement d'avancées et de reculs. J'irai peut-être, en effet, te rendre hommage dans ce pays où joie et trépas se donnent la main à la fête des Morts. Te verrai-je dans la foule? Comme jadis je t'ai aperçu, peu après ta disparition, au centre de Rio de Janeiro, sur l'avenida Rio Branco: tu regardais défiler les gagnants du deuxième groupe des écoles de samba et les femmes à demi nues et trémoussantes, préliminaires du carnaval. Une apparition? une incorporation? une coïncidence? une concentration de tout mon être pour te réinventer? C'était toi, ton si beau profil, mais sans doute un autre, né au Brésil, ton frère jumeau sous les Tropiques. Ce Brésil où j'ai fui peu après ta mort et où, souvent, tu m'es apparu, de jour comme de nuit. En songe, pour compenser la saudade de toi dans ma vie éveillée, plus d'une fois, tu m'as fait rire. Tu étais vivant et nous marchions ensemble de ce pas qui correspondait bien à ton nom. Walker. Dis-moi: les

* Lauréate en 2002 d'un prix du roman de la Société des écrivains canadiens (section Montréal) pour Désert désir ainsi qu'un prix du Conseil des arts et des lettres du Québec pour Laval. Directrice de la revue Brèves littéraires.

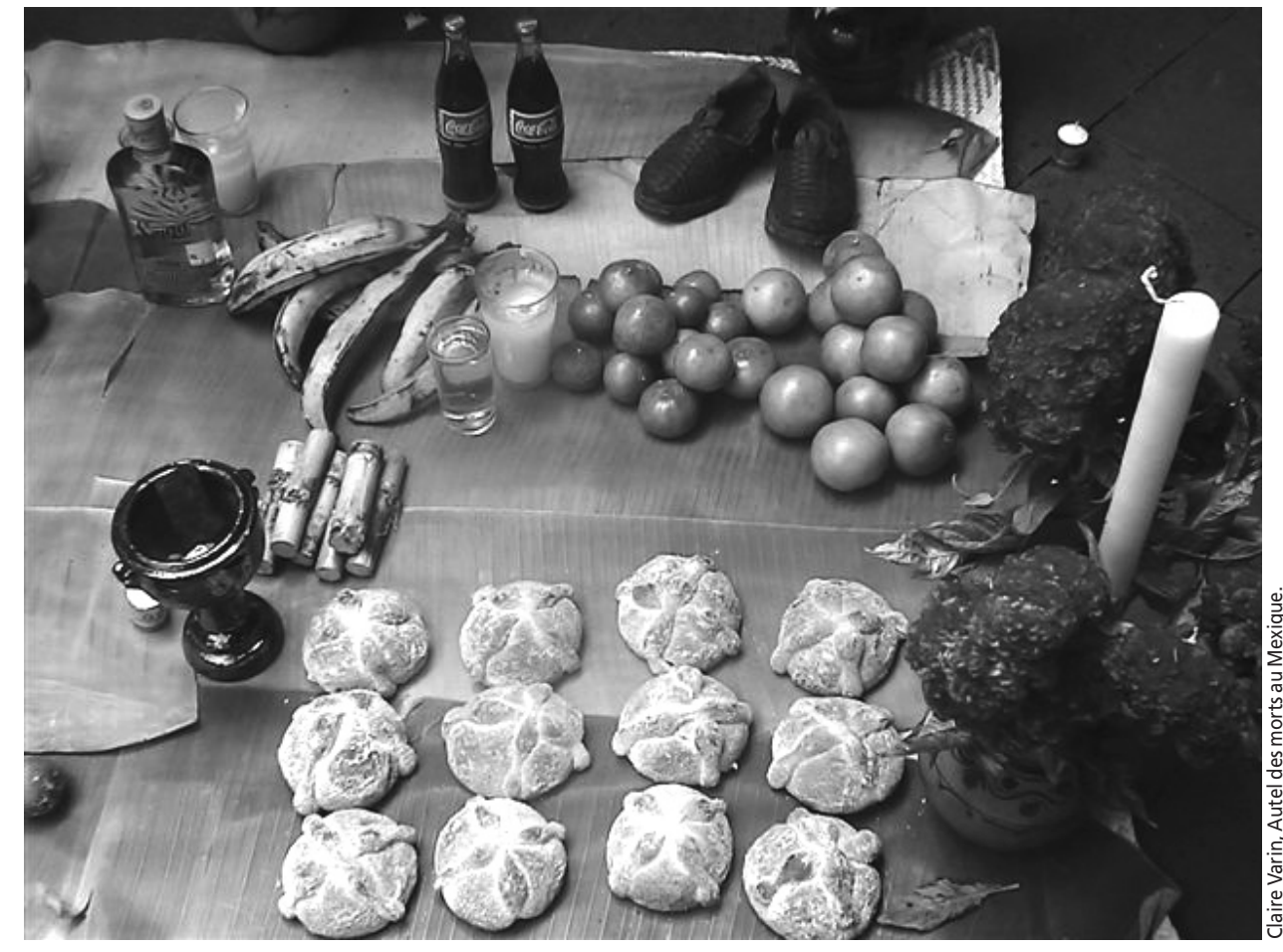

morts ne meurent donc jamais? Ils circulent d'une tête de vivant à l'autre jusqu'à la fin des temps?

$$
* * *
$$

Dimanche je suis revenue du Mexique où tes yeux m'ont suivie. Un pèlerinage secret m'y a conduite alors que je participais à une Rencontre de traducteurs littéraires, couverture officielle d'un projet de voyeurisme dans les maisons et cimetières mexicains à l'occasion $\mathrm{del}$ Dia de los Muertos.
Dans tous les coins du pays, on cuisine le traditionnel "pain du mort», légèrement sucré, en forme de tombe, comme celui que m'a servi au déjeuner une belle vieille du Colegio de Mexico où j'étais hébergée. Partout, des autels domestiques et commerciaux en hommage aux défunts. Le 31 octobre, on célèbre les assassinés et les victimes d'accident (c'est toi, ça), le $1^{\mathrm{er}}$ novembre, les enfants disparus et le 2, les adultes en allés. Sur l'autel, 
ce que le mort aimait boire et manger, quelques effets personnels, des photos, un lampion toujours allumé et ces fleurs qu'on appelle ici œillets d'Inde et qui, là-bas, prennent un nom náhualt imprononçable qui n'existe même pas dans mes dictionnaires espagnols: zempaxúchitl, aussi écrit cempasúchiles. Un nom extraterrestre.

Je savais bien, Malcolm, que j'avais raison de ressasser ta mémoire. Même que je n'en ai pas fait assez... Là-bas, ils approuvent les rituels funèbres individuels et, en dépit du passage des ans, tout un chacun en remet, ressortant invariablement le sombrero du défunt pour l'exposer sur leur autel particulier. Quand ce ne sont pas ses souliers. Ici, on taxerait de malsaine cette constance. Ici, il faut vite se débarrasser des vêtements du mort, effacer ses traces, redécorer sa chambre, sinon on juge bientôt l'endeuillé inapte à surmonter la perte... Imagine si j'érigeais un autel chez moi pour célébrer ta mort: avec tes bottes de travail, une bouteille de bière et ta photo recollée, celle que tu avais déchirée un jour de colère parce que tu me reprochais de ne chérir que ton image. J'ai un peu honte de constater ne pas me souvenir de tes mets préférés... Pas de fruits mais de la viande en tout cas; pas de légumes mais du pain. La photo de ma siamoise qui t'a rejoint un jour dans la mort, et que tu aimais. Le petit chat que tu portais en pendentif suspendu à une chaînette en or, cachée sous tes vêtements. Ton large bracelet de cuivre. Et quoi d'autre? Une bête vivante, pourquoi pas? Un félin au milieu du rituel, allant et venant à sa guise. Ça te plairait, j'en suis sûre.

Au fond, je te connaissais si peu dans la vie quotidienne. Il me faut inventer les objets à déposer sur ton autel.

La calavera tiene ambre... La tête de mort a faim...

C'est ce que les enfants déguisés en squelette répètent en sonnant aux portes les soirs de 31 octobre, ou penchés à la portière des voitures, pour ramasser des bonbons ou quelques sous. As-tu faim, tête de mort? Malcolm? Tête de mort? Je blague. Tu es tête de vivant. Tête de mort, tu n'existes pas.

La fête des Morts. Ta fête. Je te la fis et te la fais encore, toi qui n'es pas un «mort frais», comme disent les habitants de l'État de Guerrero. Tes yeux verts rutilant comme des émeraudes entre les objets de cultes individuels, ta chevelure noire et épaisse à l'image de celle des Mexicains, et qui flotte sur une absence de visage. Tu cours entre les pyramides de Xochicalco que je visite au crépuscule, tu te sens jeune, tu es heureux de voyager avec moi au Mexique. Tu survis parmi les ruines.

Grâce à moi. Toute-puissante, je règne sur ta double vie. Je décide de te ressusciter plutôt que de te tuer. Le 2 novembre, tu m'accompagnes dans le cimetière de Tepotzlan, veillé à l'horizon par de hautes montagnes. Ici, une débauche de zempaxúchitl achetés aux marchandes à l'entrée du cimetière et disposés en forme de croix sur les pierres tombales agglutinées les unes contre les autres comme des chiots apeurés. Un entassement de niches et monuments bétonnés, une orgie de crêtes-de-coq rouges. Partout, des fleurs couchées, assoiffées, ou debout, les pieds mouillés dans des boîtes de conserve ou des vases en plastique. Des glaïeuls aussi et des bougies allumées. En bordure des allées fleuries, des mariachis en action, activité musicale non exportable dans les cimetières nord-américains. Ce lieu n'est pas un jardin des allongés: trop de couleurs vives et de gens à la verticale, disséminés. Les enfants voltigent tels des papillons. Bouquet d'œillets d'Inde sous le bras ou sceau d'eau à la main, leurs parents se dirigent vers la stèle à nettoyer sous le soleil, quand ils ne sont pas déjà en train de s'affairer au-dessus des restes de leurs descendants ou assis sur une tombe en train de converser. Difficile, en déambulant, d'éviter les pierres funéraires... Au détour d'une tombe bleue, une femme seule sanglote, adossée à un muret, dont je m'éloigne par pudeur. Enfin, quelqu'un qui pleure.

Mais je mens quand j'affirme que tu m'as suivie partout en contrée mexicaine. Malgré la fantastique énergie de la fête des Morts qui battait son plein, tu manquais à l'appel. Depuis si longtemps as-tu quitté ton corps. Près d'un quart de siècle maintenant. C'est ma fiction qui te fait voyager. Vois comme je suis apparemment fidèle aux amours mortes. En réalité, j'entretiens ta mémoire en pur désir d'écriture. Tu es mon exercice de récupération, mon apprentissage du mensonge dans ma quête de la vérité, ma tentative de télescopage du temps. 